\title{
ARMAZENAMENTO DO GRÃO DE PÓLEN DE CEBOLA (Allium cepa L.) ${ }^{1}$
}

\author{
PATRÍCIA ROCHA GOMES ${ }^{2}$, MARIA DO CARMO B. RASEIRA ${ }^{3}$, LEOPOLDO L. BAUDET ${ }^{4}$, SILMAR T. PESKE ${ }^{5}$
}

\begin{abstract}
RESUMO - Experimentos foram conduzidos no Laboratório de Melhoramento Genético da Embrapa Clima Temperado, em Pelotas, RS, com o objetivo de avaliar, in vitro, o potencial de armazenamento dos grãos de pólen de cebola da cv. Petrolini, em diferentes condições por dois anos. Para tanto, avaliou-se a percentagem de germinação do grão de pólen após um e dois anos de armazenamento em criotubos, acondicionados em nitrogênio líquido (-196º $\mathrm{C})$, e em frascos de vidro acondicionados no interior de dessecador contendo ácido sulfúrico e mantidos em freezer $\left(-18^{\circ} \mathrm{C}\right)$. O pólen conservado por um ano em nitrogênio líquido foi então transferido para um refrigerador, registrando-se a percentagem de germinação após 10, 15, 20 e 30 dias de permanência neste. $\mathrm{O}$ armazenamento em nitrogênio líquido foi o melhor ambiente para a conservação dos grãos de pólen durante dois anos. As amostras armazenadas, por um ano, em nitrogênio líquido, que foram transferidas para refrigerador, conservaram-se viáveis por até dez dias.

Termos para Indexação: nitrogênio líquido, refrigerador, germinação in vitro.
\end{abstract}

\section{ONION (Allium cepa L.) POLLEN STORAGE}

\begin{abstract}
Experiments using the onion cultivar Petrolin, were conducted at the EMBRAPA Plant Breeding Laboratory, Pelotas, RS, with the objective of evaluating "in vitro" the potencial of onion pollen stored up to two years and stored under different conditions for two years. Pollen germination was determined after one and two years of storage in chriotubes conditioned in liquid $\mathrm{N}\left(-196^{\circ} \mathrm{C}\right)$ and in glasses in a desiccator with sulfuric acid kept in a freezer $\left(-18^{\circ} \mathrm{C}\right)$. The pollen stored for one year in liquid $\mathrm{N}$ was transferred to a refrigerator and the germination percentage was evaluated at 10, 15, 20 and 30 days. Storage in liquid nitrogen was the best method for conserving pollen for two years. Samples stored for one year in liquid nitrogen and then transferred to a refrigerator kept viability for ten days.

Index Terms: liquid nitrogen, refrigerator, in vitro germination.
\end{abstract}

\section{INTRODUÇÃO}

O armazenamento de grãos de pólen por período superior a um ano é importante para a preservação de germoplasma, desenvolvimento de pesquisas com pólen, promoção de intercâmbio de germoplasma e melhoria da eficiência dos programas de melhoramento (Hanna, 1994).

De acordo com Ganeshan (1986), uma alternativa para a perpetuação de linhagens mantenedoras dos híbridos, na cultura da cebola, seria mediante o armazenamento do pólen dessas plantas, pois possibilitaria a realização de cruzamentos sem a necessidade do cultivo alternado dessas linhagens polinizadoras, em campo.

O sucesso da preservação do pólen, independentemente da duração do período de conservação, depende principalmente de fatores como a temperatura e umidade relativa do ambiente de armazenamento e do grau de umidade do pólen (Linskens, 1964; Dean, 1965; Khan et al., 1971).

Ganeshan (1986) armazenou amostras de pólen de Allium сера L. em nitrogênio líquido $\left(-196^{\circ} \mathrm{C}\right)$, durante 360 dias,

\footnotetext{
${ }^{4}$ Eng ${ }^{\circ}$ Agro ${ }^{\circ}$, Ph.D., FAEM/UFPel; Cx. Postal 354, 96010-900, Pelotas, RS; e-mail: lmbaudet@ufpel.tche.br

${ }^{5}$ Eng $^{\circ}$ Agr $^{\circ}$., Dr., FAEM/UFPel; Cx. Postal 354, 96010-900, Pelotas, RS; email: peske@ufpel.tche.br
} 
verificando que a duração do armazenamento não influenciou a viabilidade e capacidade de fertilização do pólen desta espécie. Por sua vez, Kanazawa et al. (1992) encontraram uma alta percentagem de germinação para o pólen de espécies do gênero Allium, após o armazenamento por um ano em nitrogênio líquido. Os autores sugeriram que este pólen poderia continuar viável por um período superior a um ano.

O pólen da cultivar Petrolini foi armazenado pelo período de um ano em nitrogênio líquido e no interior de um dessecador com ácido sulfúrico mantido em congelador $\left(-18^{\circ} \mathrm{C}\right)$, por Gomes et al. (2000 a). Os autores constataram que a melhor condição para o armazenamento foi em nitrogênio líquido. Foi sugerido que o aumento do tamanho das amostras de pólen colhidas poderia elevar o baixo valor de germinação, encontrado para esta cultivar, pois devido a desuniformidade na abertura das inflorescências, numa amostra haveria pólen com diferentes estádios de desenvolvimento o que influenciaria diretamente a percentagem de germinação.

Este trabalho teve como objetivo avaliar, in vitro, o potencial de armazenamento dos grãos de pólen da cv. Petrolini, até o período de dois anos, assim como do pólen conservado por um ano em nitrogênio líquido $\left(-196^{\circ} \mathrm{C}\right)$ que foi armazenado por 30 dias em refrigerador $\left(5^{\circ} \mathrm{C}\right)$.

\section{MATERIAL E MÉTODOS}

O trabalho foi realizado no Laboratório de Melhoramento Genético, pertencente à Embrapa Clima Temperado (CPACTEMBRAPA), em Pelotas-RS. Foi utilizada a cultivar comercial de A. cepa, Petrolini, proveniente dos campos de produção de sementes do Centro Regional de Pesquisa FepagroSul, pertencente à Fundação Estadual de Pesquisa Agropecuária (FEPAGRO), localizada em Rio Grande-RS.

A metodologia de preparo para a secagem dos grãos de pólen para o armazenamento nas diferentes condições foi à estabelecida por Gomes (1998). As amostras da mistura de pólen e antera da cv. Petrolini, colhidas de 260 umbelas, no ano de 1998, foram armazenadas em nove criotubos, no interior de um botijão de nitrogênio líquido $\left(-196^{\circ} \mathrm{C}\right)$ e em congelador $\left(-18^{\circ} \mathrm{C}\right)$, em quatro vidros tampados com algodão, mantidos no interior de dessecador contendo ácido sulfúrico, como substância higroscópica, durante um e dois anos. A umidade relativa no interior do dessecador contendo ácido sulfúrico foi mantida entre 25 e 50\%, através da utilização de uma solução composta de $23 \mathrm{ml}$ de $\mathrm{H}_{2} \mathrm{SO}_{4}$ e $50 \mathrm{ml}$ de $\mathrm{H}_{2} \mathrm{O}$ destilada (Medeiros, 1976; Camargo, 1978).
A avaliação da viabilidade do pólen foi feita pelo teste de germinação in vitro, utilizando-se o meio determinado por Gomes et al. (2000 b), registrando-se a germinação inicial das amostras e após um e dois anos de armazenamento, em cada uma das duas condições, assim como para aquelas que após um ano à $-196^{\circ} \mathrm{C}$, foram armazenadas por 10, 15, $20 \mathrm{e}$ 30 dias, em refrigerador. Para estas avaliações, foram retirados grãos de pólen de cada um dos tratamentos e, os mesmos, retornaram para os respectivos ambientes de conservação imediatamente após a retirada das amostras.

Para o ensaio com o pólen armazenado, por um e dois anos, foram considerados dois ambientes de armazenamento (nitrogênio líquido e congelador) e três períodos de duração do armazenamento (germinação inicial, após um e após dois anos). O número de repetições foi cinco, sendo cada uma constituída por uma placa de Petri, contendo uma lâmina adaptada (Mendes, 1994).

No ensaio com o pólen armazenado por um ano em nitrogênio líquido e que foi transferido para o refrigerador $\left(5^{\circ} \mathrm{C}\right)$, foi considerado como fator o período de armazenamento, em cinco níveis (pólen armazenado por um ano, em nitrogênio líquido, e por 10, 15, 20 e 30 dias em refrigerador) o qual foi repetido quatro vezes, sendo cada repetição igual a do ensaio anterior.

Realizou-se a análise estatística, adotando-se o delineamento experimental inteiramente casualizado. Os dados, expressos em percentagem, foram transformados em arco seno da raiz quadrada de $\mathrm{X} / 100$, onde $\mathrm{X}$ representa o valor percentual obtido para cada variável. Os dados qualitativos foram avaliados pelo teste de Duncan, utilizandose a de 0,01 e 0,05 e os quantitativos pela regressão polinomial.

\section{RESULTADOS E DISCUSSÃO}

Tomando por base a análise de variação realizada, verificou-se que os fatores ambientes e duração do armazenamento, assim como a interação entre os mesmos foi altamente significativa $(\alpha=0,01)$. O desdobramento das médias, pelo teste de Duncan, mostrou que o armazenamento em nitrogênio líquido foi o melhor ambiente para a conservação dos grãos de pólen durante dois anos (Figura 1).

Não houve diferença significativa na germinação do pólen em função dos ambientes de armazenamento durante o primeiro ano, (43,56\% para conservação em nitrogênio líquido e 43,19\% para conservação em freezer); porém, com relação à germinação inicial, ocorreu redução 


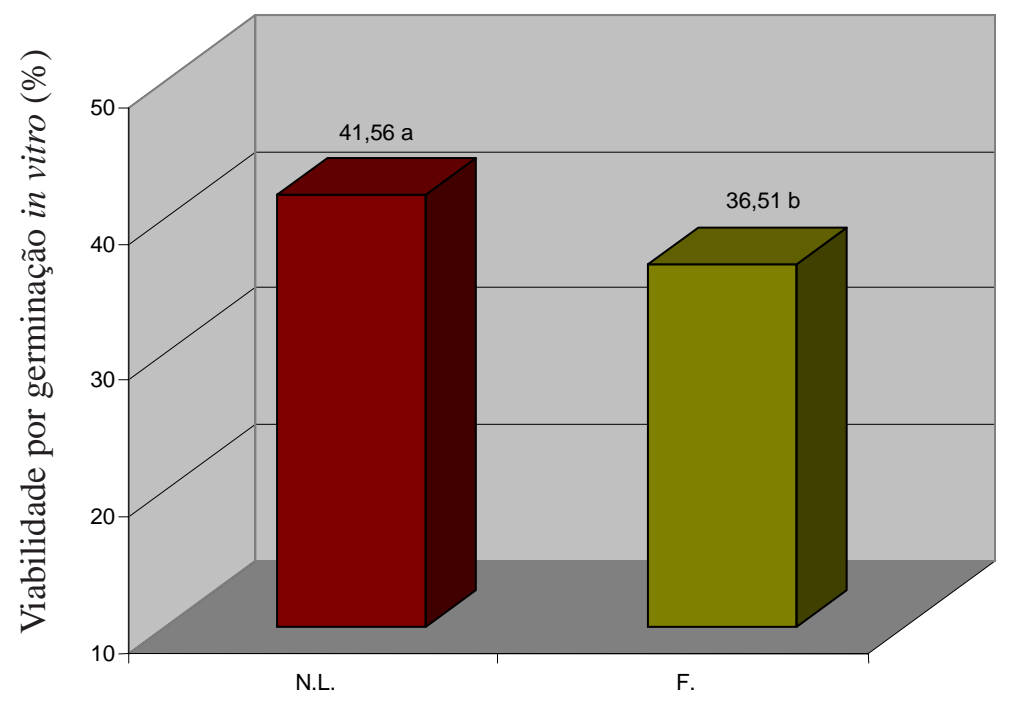

Ambiente de armazenamento

FIG. 1. Percentagem média de germinação do pólen da cv. Petrolini, armazenados por dois anos, em nitrogênio líquido (N.L.), e em freezer (F.).

Médias seguidas por letras distintas diferem entre si pelo teste de Duncan, com $\alpha=0,01)$. Pelotas-RS, 2001.

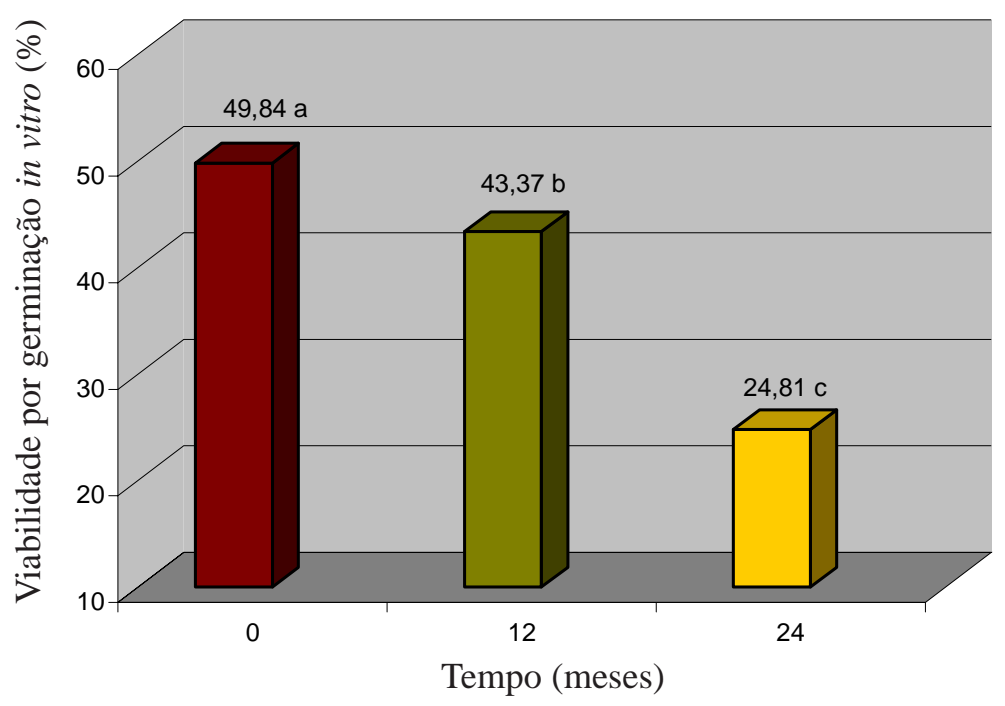

FIG. 2. Percentagem média de germinação do pólen da cv. Petrolini, antes do armazenamento (0), após 12 e 24 meses de armazenamento a $-196^{\circ} \mathrm{C} \mathrm{e}-18^{\circ} \mathrm{C}$.

Médias seguidas por letras distintas diferem entre si pelo teste de Duncan, com $\alpha=0,01$. Pelotas-RS, 2001.

significativa na percentagem de germinação das amostras, em ambos os ambientes, até o segundo ano de armazenamento (Figura 2).
Estes resultados concordam com Ganeshan (1986) e Kanazawa et al. (1992), onde uma alta percentagem de germinação foi verificada para o pólen de espécies do gênero Allium, após o armazenamento em nitrogênio líquido, por um ano, tendo os autores, sugerido que o pólen poderia continuar viável, por período superior. Também, Gomes et al. (2000 a) constataram que a melhor condição para o armazenamento deste pólen foi em nitrogênio líquido e, com o presente trabalho, podese verificar que, como a quantidade de pólen colhido foi maior (retirado de 260 umbelas), os valores de germinação, tanto para as amostras conservadas em nitrogênio líquido (41,56\%) como em congelador (36,51\%), ao final dos dois anos de armazenamento foram superiores àquelas obtidas no trabalho anterior $(27,47$ e 19,23\%, respectivamente), porém, após um ano de armazenamento. Tais resultados confirmaram a suposição dos autores de que aumentando o tamanho da amostra de pólen, a percentagem de germinação do pólen da cultivar Petrolini também tenderia a aumentar. Este fato seria explicado pelo efeito de sinergismo dos grãos de pólen, ou seja, uma estimulação mútua entre eles, que faz com que germinem melhor quando agrupados em maior quantidade (Branscheidt, Savelli, e Linskens \& Kroh, citados por Stanley \& Linskens, 1974). Além disso, Mann \& Woodbury (1969) constataram que os maiores índices de germinação do pólen de A. cepa ocorreram no primeiro dia após a antese $(40,80 \%)$, diminuindo após o terceiro dia da abertura das inflorescências $(23,38 \%)$ e chegando próximo a zero $(4,26 \%)$ no sexto dia após a antese. Ockendon \& Gates (1976) salientaram que ocorre uma grande diferença na viabilidade do pólen entre anteras dentro de uma mesma flor e entre flores dentro de uma mesma umbela.

Pela análise de regressão polinomial para os níveis do fator período de armazenamento do pólen, que foi transferido para o refrigerador, depois de conservado em nitrogênio líquido, por um ano, verificou-se que houve tendência à redução da sua capacidade de germinação, com o passar do tempo (Figura 3). Entretanto, verificou-se redução acentuada na germinação do pólen após dez dias de armazenamento em refrigerador. Portanto, a conservação a $5^{\circ} \mathrm{C}$, desde que não ultrapasse o período de dez dias, pode ser utilizada como alternativa para o armazenamento de amostras provenientes de outras localidades, até que as mesmas sejam utilizadas em cruzamentos. 


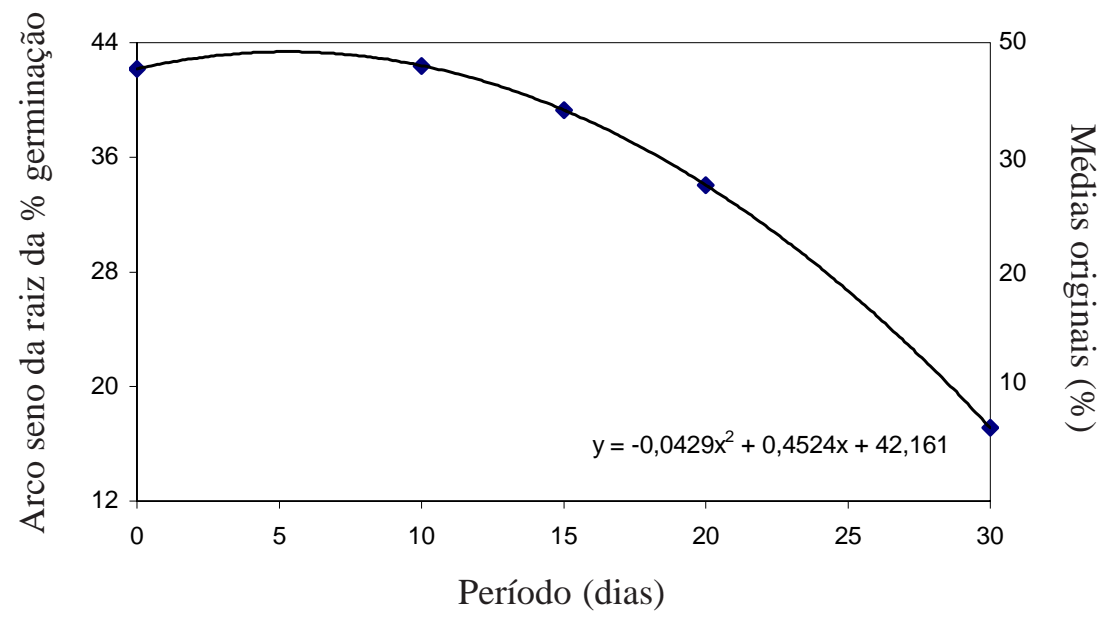

FIG. 3. Regressão polinomial para a percentagem de germinação do pólen da cv. Petrolini, armazenado por um ano em nitrogênio líquido (0), e mantido em refrigerador por 10, 15, 20 e 30 dias. Pelotas-RS. 2001.

Já Vazil, citado por Stanley \& Linskens, (1974), verificou que a capacidade de fertilização do pólen de milho, medida pela produção de sementes, foi mantida somente por seis dias, em armazenamento a $2^{\circ} \mathrm{C}$.

De acordo com Dobouzet et al. (1993), cruzamentos entre espécies do gênero Allium poderiam ser realizados com o pólen que manteve sua germinabilidade por oito meses, quando armazenado em dessecador com sílica gel, à temperatura de $2-3^{\circ} \mathrm{C}$. Resultados similares foram encontrados por Nomura et al. (1994), ao armazenar grãos de pólen de A.cepa em recipientes contendo sílica gel, como agente dessecante, onde a germinação das amostras conservadas a $5^{\circ} \mathrm{C}$ diminuiu nos primeiros seis meses de armazenamento, chegando a $0 \%$, aо final de um ano. Entretanto, aquelas conservadas a $-30^{\circ} \mathrm{C}$ permaneceram viáveis após dois anos de armazenamento.

\section{CONCLUSÕES}

A melhor condição para o armazenamento dos grãos de pólen de cebola, durante o período de dois anos, é em nitrogênio líquido.

A transferência das amostras armazenadas, por um ano em nitrogênio líquido para refrigerador, por até dez dias, é alternativa viável.

\section{AGRADECIMENTO}

Ao CNPq, pela concessão da bolsa de estudo que possibilitou a realização desta pesquisa.

\section{REFERÊNCIAS}

CAMARGO, U.A. Comportamento de algumas cultivares e seleções de macieira (Malus pumila Mill.), quanto à polinização, na região sul do Rio Grande do Sul. 1978. 62f. Dissertação (Mestrado) Universidade Federal de Pelotas, Pelotas.

DEAN, C.E. Effects of temperature and humidity on the longevity of tobacco (Nicotiana tabacum L.) pollen in storage. Crop Science, v. 11, p. 125-127, 1965.

DUBOUZET, J.G.; SHIMOFURUTACHI, M.; ARISUMI, K.; ETOH, T.; MATSUO, E.; SAKATA, Y. Improvement of pollen germinability and storability in some Japanese Alliums. Memoirs of the Faculty of Agriculture Kagoshima University, v. 29, p. 6774, 1993.

GANESHAN, S. Viability and fertilizing capacity of onion pollen (Allium cepa L.) stored in liquid nitrogen (-196 ${ }^{\circ}$ C). Topical Agricultural, v. 63, n. 1, p. 46-48, 1986.

GOMES, P.R. Viabilidade e conservação do grão de pólen de cebola (Allium cepa L.). 1998. 54 f. Tese (Mestrado) - Universidade Federal de Pelotas, Pelotas.

GOMES, P.R.; GARCIA, A.; RASEIRA, M. do C.R.; SILVA, J.B. da. Coleta e conservação de pólen de cebola (Allium cepa L.). Agropecuária Clima Temperado, v.3, n.1, p.19-29, 2000 a.

GOMES, P.R.; GARCIA, A.; RASEIRA, M. do C.R.; SILVA, J.B. da Germinação in vitro do pólen de cebola (Allium cepa L.). Agropecuária Clima Temperado, v.3, n.2, p.193-198, 2000 b.

HANNA, W.N. Pollen storage in frostless and conventional frostforming freezers. Crop Science, v.34, p.1681-1682, 1994.

KANAZAWA, T.; KOBAYASHI, S.; YAKUWA, T. Flowering process, germination and storage of pollen in Allium victorialis $\mathrm{L}$. spp. platyphyllum Hult. Journal of the Japanese Society for Horticultural Science, v.60, n.4, p.947-953, 1992.

KHAN, M.N.; HEYNE, E.C.; GOSS, A.E. Effect of relative humidity on viability and longevity of wheat pollen. Crop Science, v.11, p.125127, 1971.

LINSKENS, H.F. Pollen physiology. Annual Review Plant Physiology, v.14, p.225-226, 1964.

MEDEIROS, A.R.M. de Sobre o efeito da temperatura e umidade relativa na percentagem de frutificação efetiva e influência da temperatura na germinação dos grãos de pólen e crescimento do tubo polínico em pessegueiro (Prunus persica (L.) Batsch). 1976. 46f. Dissertação (Mestrado) - Universidade Federal de Pelotas, Pelotas.

MENDES, M. da S. Viabilidade do grão de pólen de Solanum spp. 1994. 75f. Dissertação (Mestrado) - Universidade Federal Pelotas, Pelotas.

NOMURA, Y.; MAEDA, M. TSUCHIYA, T.; MAKARA, K. Efficient production of interspecific hybrids between Allium chinense and edible Allium spp. through culture and pollen storage. Breeding Science, v.44, p.151-155, 1994.

STANLEY, R.G.; LINSKENS, H.F. Pollen: biology, biochemistry, management. Berlin: Heidelberg, 1974. 307 p. 